\title{
Direitos humanos e o acesso à educação em bioética para a graduação e a pós-graduação em educação física
}

https://doi.org/10.11606/issn.1981-4690.v35inespp47-54

\author{
Luciana Teixeira Waltrick* \\ Alcyane Marinho*
}

\section{Resumo}

Este ensaio teórico tem como objetivos: 1) demonstrar a importância do ensino em Bioética para os profissionais da área da Educação Física; (2) defender o ensino da Bioética nos cursos de graduação e de pós-graduação em Educação Física; e (3) apresentar a Bioética de enfoque latino-americano como proposta para analisar os Direitos Humanos no Brasil no contexto da Educação Física. Para tanto, entendemos o ensaio teórico como uma apresentação de natureza reflexiva e interpretativa, de julgamento pessoal dos próprios pesquisadores, embasados em literatura científica existente sobre o tema abordado. A Bioética associada às Ciências do Movimento Humano, ao esporte de alto rendimento, à atividade física e à saúde traz à tona questões complexas como: imagem corporal, anorexia, vulnerabilidade do atleta profissional e conflitos bioéticos envolvidos no relacionamento entre 0 atleta profissional e o profissional da saúde que 0 atende, a iniciação esportiva precoce, além da importância do profissional da Educação Física, como agente educador, inserido em políticas públicas para uma sociedade que se apresenta sedentária e estigmatizada. Diante das aproximações dos conflitos bioéticos que os avanços tecnológicos promovem nas profissões da área da saúde, há a necessidade de se discutir sobre a importância do ensino da Bioética na formação acadêmica dos profissionais da área da saúde e, assim, prepará-los para refletir sobre os possíveis conflitos éticos que encontrarão durante a atuação profissional. Estes que, por sua vez, possuem uma profunda e complexa relação com os direitos humanos.

Palavras-chave: Temas bioéticos; Formação profissional; Educação superior; Atividade motora.

\section{Introdução}

O Conselho Federal de Educação Física (CONFEF) e seus conselhos regionais realizaram, no ano de 2005, o "III Seminário de Ética" visando discutir a temática "Ética e Bioética", no contexto da Educação Física, demonstrando o interesse que as temáticas despertaram na categoria profissional da área já naquele ano. $\mathrm{O}$ resultado do encontro foi organizado na obra intitulada "A Ética e a Bioética na Preparação e na Intervenção do Profissional de Educaçáo Física" . A Bioética, como um estudo interdisciplinar, "que se desenvolve sobre o conjunto de condiçóes da vida humana e da natureza, na estreita relação de vivência e convivência do Ser humano", necessita atenção responsável devido à velocidade com que ocorrem os complexos progressos do saber. Portanto, é necessária para todas as profissōes, em especial, aos profissionais da Educação Física que submetem os seres humanos a diferentes tipos de relacionamentos entre pessoas e em distintas situações ambientais ${ }^{2}$. Assim como também é necessária nas Ciências do Movimento Humano $(\mathrm{CMH})$ que tratam da totalidade humana; isto é, do corpo, do espírito, da natureza e da sociedade, sendo esta ciência o sistema que compreende os subsistemas esporte, dança, ergonomia e motricidade terapêutica ${ }^{3}$.

É nesta diversidade do campo de intervenção dos profissionais da saúde que trabalham com o corpo em movimento que são necessárias reflexóes éticas tais como: a falta de acesso de qualidade aos benefícios da Educação Física e do esporte, assim como o acesso dos idosos e deficientes a estes benefícios; assim como o desejo de vitória a qualquer custo estimulando o uso de substâncias ilícitas para melhorar o desempenho, bem como o alto nível de exigência no desempenho de crianças no esporte ${ }^{4}$.

A Bioética surgiu interdisciplinarmente, com uma abordagem global da pessoa (corpo e espírito), 
inserida em uma família e influenciada por um meio, e uma abordagem social, interessada nas estruturas sociais, com justiça e equidade, considerando as escolhas de valores de uma sociedade. Portanto, a Bioética diz respeito à decisão e à ação por meio da reflexão ética juntamente com conhecimentos distintos de cada problema bioético apresentado que pode ser um caso clínico, uma pesquisa a ser avaliada, ou diretrizes e políticas de saúde a serem estabelecidas 5 .

Diante destas consideraçóes, podemos verificar a importância da Declaração Universal sobre Bioética e Direitos Humanos (DUBDH) ${ }^{6}$, que foi homologada pela Organizaçáo das Naçóes Unidas para a Educação, a Ciência e a Cultura (UNESCO) e assinada por 191 países. Este documento se constitui em uma ferramenta de reflexão ética para que os governos e os gestores estabeleçam leis e normas para orientar as políticas de proteção à saúde, bem como se apresenta como um novo referencial epistemológico para uma Bioética mais próxima dos conflitos que persistem e assolam a maioria dos países ${ }^{7}$. Este documento permitiu ampliar os limites biomédicos e biotecnológicos da Bioética e estimular o debate sobre questôes sociais que podem diminuir as capacidades e potencialidades dos socialmente mais frágeis ao afetar a qualidade de vida destes ${ }^{8}$.

As discussōes em relação ao ensino da Bioética são iminentes na graduação e na pós-graduação de profissionais da saúde, porém, pode-se perceber que a introdução da Bioética em matrizes curriculares ainda se mostra incipiente, conforme demonstra o estudo de Figueiredo, Garrafa e Portillo?. Estes autores realizaram uma revisão sistemática entre 2000 e 2007 para conhecer as produçóes científicas sobre o ensino da Bioética na área das Ciências da Saúde no Brasil e obter um panorama da inclusão da Bioética como disciplina acadêmica na graduação e na pós-graduação na área da saúde. Os autores concluíram que o interesse pela temática estava iniciando e grande parte da produção de literatura dizia respeito à área médica. Além disso, verificaram que a Bioética estava tão agregada à ética médica que, muitas vezes, passava a ser confundida como sinônimo. As produçôes científicas, até aquele momento, não foram suficientes para permitirem uma avaliaçáo nacional dos cursos que ofereciam a disciplina autônoma ou como conteúdo ministrado transversalmente durante o curso. Porém, neste estudo, os autores ${ }^{9}$ demonstraram um consenso quanto à necessidade de tornar a Bioética uma disciplina acadêmica.
Em levantamento realizado nos cursos de Pós-graduação Stricto Senso da grande área das Ciências da Saúde avaliados e reconhecidos pela Coordenaçáo de Aperfeiçoamento de Pessoal de Nível Superior (CAPES), que possuíam a disciplina de Bioética, foram encontrados 163 cursos distribuídos em nove das doze áreas que fazem parte da grande área das Ciências da Saúde: Enfermagem, Farmácia, Fonoaudiologia, Medicina, Nutrição, Odontologia e Saúde Coletiva. As áreas da Educação Física, Fisioterapia e Terapia Ocupacional não apresentaram nenhum curso de mestrado ou de doutorado com a disciplina de Bioética ${ }^{10}$. Em levantamento realizado em 2019 na Plataforma Sucupira, na área 21, em especial, na Educação Física, foram verificados somente quatro cursos de pós-graduação em $\mathrm{CMH}$ que ofereciam a disciplina de Bioética ${ }^{11}$.

Alguns estudos demonstram a necessidade de se discutir sobre a importância do ensino da Bioética na formação acadêmica dos profissionais da área da saúde e, assim, prepará-los a refletir sobre os possíveis conflitos éticos que encontrarão durante a atuação profissional ${ }^{11-13}$. Diante da diversidade de assuntos, o ensino-aprendizagem seria mais eficaz se fosse realizado transdisciplinarmente durante toda a formação acadêmica ${ }^{14,15}$. Para além disso, em sintonia com Silveira et al. ${ }^{16}$ acreditamos que a proposição de uma educação em direitos humanos no ensino superior está diretamente relacionada à reflexáo sobre o direito à própria educação como um todo.

Em particular, alguns conflitos bioéticos descritos na literatura na área das $\mathrm{CMH}$ demonstram a necessidade de ampliar as discussôes entre os profissionais que lidam com o ser humano em movimento intencional, como, por exemplo, a vulnerabilidade do atleta profissional ${ }^{17}$ e conflitos bioéticos envolvidos no relacionamento deste atleta profissional e o profissional da saúde que o atende ${ }^{18}$; a iniciaçáo esportiva precoce ${ }^{19}$; o uso de substâncias ilícitas para melhorar o desempenho esportivo e a artificializaçáo dos corpos ${ }^{20}$. Alguns temas bioéticos, mais diretamente, relacionados aos direitos humanos são: a inclusão social, o racismo e o bullyng, entendidos como formas de discriminação ou vulnerabilidades.

Diante destas aproximaçóes dos conflitos bioéticos que os avanços tecnológicos promovem nas profissóes da área da saúde, existe a necessidade de ser discutida a importância do ensino da Bioética na formação acadêmica dos profissionais da área da saúde e, assim, prepará-los para refletir sobre os possíveis conflitos éticos que encontrarão durante a atuação 
profissional. Partindo destas consideraçóes, adotamos os pressupostos de Meneghetti ${ }^{21}$, autor quem caracteriza o ensaio teórico como uma apresentação de natureza reflexiva e interpretativa de julgamento pessoal dos próprios pesquisadores, embasados em literatura científica existente sobre o tema abordado. Assim, este ensaio teórico tem como objetivos: 1) demonstrar a importância do ensino em Bioética para os profissionais da área da Educação Física; (2) defender o ensino da Bioética nos cursos de graduação e de pós-graduação em Educação Física; e (3) apresentar a Bioética de enfoque latino-americano como proposta para analisar os Direitos Humanos no Brasil no contexto da Educação Física.

\section{Desenvolvimento e discussão}

As $\mathrm{CMH}$ são compostas por várias áreas científicas que se preocupam em responder aos diversos problemas provenientes da cultura corporal do movimento humano, atrelados aos esportes, às danças, aos jogos, às lutas, às terapias corporais, entre outros. Conforme GAYA ${ }^{22}$, elas se propóem a "analisar, interpretar, propor teorias cientificas relacionadas com o ensino, o treino, a saúde e o lazer e compreendê-las à luz dos sentidos e valores, das condiçóes e possibilidades, das normas e razóes da educação e da formação".

Assim, destaca-se a relevância de serem apresentados os conteúdos bioéticos para profissionais, pesquisadores e professores desta área, conforme discutido por WaLTRICK ${ }^{11}$, em um estudo realizado com egressos de um Programa de Pós-graduação em CMH. Este estudo demonstra o reconhecimento da importância da disciplina de Bioética, visto que esta promoveu uma ampliação do olhar dos egressos do curso, frente aos conflitos bioéticos existentes no seu ambiente profissional, facilitando tomadas de decisão, após avaliar diferentes visóes do problema. Este estudo ainda apresenta que são relevantes e pertinentes as reflexóes éticas sobre o papel do profissional relacionadas ao conjunto de medidas de prevenção contra o adoecimento e as ameaças que podem afetar a qualidade de vida de uma população, especialmente aqueles que se encontram em vulneraçáo (estado que pode deixar o ser humano desprotegido, sendo dever ético do estado e da ciência proteger a pessoa que se encontre neste estado, podendo ser associado à discriminaçáo, à pobreza, à falta de acesso à educaçấo e à saúde), promovendo justiça social ${ }^{11}$.

Para os países da América Latina, existem ferramentas teóricas e práticas da Bioética preocupadas com os conflitos bioéticos contextualizados nesses locais, que propóem a reflexão crítica sobre os variados determinantes históricos, culturais, econômicos, políticos e tecnológicos em temas que afetam a saúde e o bem-estar de indivíduos ${ }^{23}$. A Bioética de Proteção ${ }^{24}$ pode ser entendida como a parte da ética aplicada que visa entender, descrever e resolver conflitos de interesses entre quem tem os meios que o tornam competente para realizar sua vida e quem, ao contrário, não os tem. Para esta reflexão é necessário ter o cuidado entre os conceitos de proteção e autonomia e à ponderação necessária quando tais categorias entram em conflito, visto que os dois conceitos parecem ser mutuamente excludentes. Conforme Schramm ${ }^{24}$, aqui, surge a questão de como fazer para focalizar os indivíduos vulnerados e lhes fornecer a proteção necessária para desenvolver suas potencialidades e sair da condição de vulneração e, ao mesmo tempo, respeitar a diversidade de culturas, as visóes de mundo, hábitos e moralidades diferentes e que fazem parte da vida em comum. De fato, os grupos particularmente vulneráveis, ou literalmente vulnerados (ou afetados), não são capazes, por alguma razão independente de suas vontades, de se defenderem sozinhos pelas condiçôes desfavoráveis em que vivem, ou devido ao abandono das instituiçôes vigentes que não lhes oferecem o suporte necessário para enfrentar sua condição de afetados e tentar sair dela ${ }^{24}$.

A Bioética de Intervenção ${ }^{25}$, por sua vez, é apresentada como uma alternativa para analisar conflitos contextualizados em países que possuem temas bioéticos persistentes (como exclusão social, pobreza, diferentes formas de discriminação, insuficiência de recursos para a saúde pública, aborto e eutanásia). Esta Bioética de Intervenção prioriza a tomada de decisóes que privilegiem o maior número de pessoas e que, no campo individual, procure soluçóes práticas e viáveis para os conflitos identificados no contexto onde ocorrem.

Porto e Garrafa ${ }^{25}$ apresentaram a Bioética de Intervenção, a qual preconiza a priorização de políticas e tomadas de decisão que privilegiem o maior número de pessoas durante o maior espaço 
de tempo possível e que resultem nas melhores consequências. A corporeidade é utilizada como marco teórico e conceitual da Bioética de Intervenção. $\mathrm{O}$ reconhecimento do corpo como parâmetro para a intervençáo ética não se limita à dimensão fisiológica. O corpo é a materialização da pessoa, a totalidade somática, na qual estão articuladas as dimensóes física e psíquica que se manifestam de maneira integrada nas inter-relaçôes sociais e nas relaçôes com o ambiente. A escolha da corporeidade como marco das intervençóes éticas se deve ao fato de o corpo físico ser inequivocamente a estrutura que sustenta a vida social, em toda e qualquer sociedade. Dessa forma, é possível avaliar a desigualdade social não apenas por parâmetros objetivos, que podem mensurar diferenças econômicas e sociais, mas também por critérios subjetivos, que indicam a correlação direta entre a percepção da pessoa e a realidade fenomenológica que a cerca ${ }^{26}$.

As pessoas com deficiência no Brasil encontramse inseridas em um contexto social bastante diverso daquelas que vivem em países desenvolvidos. Por essa razão, a Bioética de Proteção e a Bioética de Intervenção indicam a urgência de atitudes políticas que podem minimizar a fragilidade dos oprimidos e excluído ${ }^{27}$. Bernardes et al. ${ }^{27}$ também frisam que o envelhecimento acentuado e acelerado da população brasileira, e as limitaçóes físicas e psíquicas severas certamente atingirão um contingente cada vez maior de cidadáos, tornando inadiável este debate ético. Para a Bioética de Proteção, a justiça, que é universal, deve ser aplicada às necessidades específicas dos mais susceptíveis, focalizando as ações sociais a favor dos mais necessitados. Isto significa assumir que aqueles que têm menos recursos deverão receber mais proteçáo do Estado ${ }^{27}$.

Em particular, a inclusão social foi discutida no ambiente da Educação Física escolar por Barroso e DARIDO ${ }^{28}$ que defenderam a necessidade de uma Educação Física escolar direcionada para a cidadania e para a possibilidade de todos terem acesso ao conteúdo esporte, sem restriçóes de condiçôes físicas ou níveis de habilidades motoras, respeitando as diferenças entre os alunos. Os autores elegeram a cultura corporal de movimento como referência para a Educação Física escolar, procurando garantir o acesso a essa cultura, propiciando ao aluno condições de conhecê-la, reproduzi-la, reconstruí-la e transformá-la. Nesta mesma direção, Aguiar e DuARTE $^{29}$ abordaram a contribuiçãao da Educação Física escolar para o exercício da cidadania quando o professor utiliza o princípio da inclusão, priorizando o aluno e procurando desenvolver as competências de todos os discentes e dar aos mesmos condiçóes para que tenham acesso aos conteúdos a que se propóe, com participação plena, adotando, para tanto, estratégias adequadas, evitando a exclusão ou a alienação.

Ao tratar da inclusão social, Barroso e DARIDO ${ }^{28}$ explicam que os Parâmetros Curriculares Nacionais da Educação Física não se referem apenas aos alunos deficientes, ou aos que apresentam determinados problemas neurológicos, mas, envolvem a ampla preocupaçáo de todos estarem realmente inseridos no processo de ensino e aprendizagem. Para estes autores, quando o homem produz cultura, o corpo está inserido neste processo, independentemente do conhecimento que ele está transformando. Por sua vez, a utilização do corpo faz parte de qualquer processo de aprendizagem.

BARRoso e DARIDO ${ }^{28}$ acreditam que a chamada escola democrática deve respeitar a individualidade de cada pessoa e oferecer uma educaçáo com maior abrangência e qualidade. A escola não deve focar apenas em preparar para o mercado, mas possuir uma funçáo mais humanizadora com o foco no Ser Humano. Para os autores, a escola participa ativamente da educação para a cidadania e significa que as pessoas tenham possibilidades de acesso aos direitos, por meio de igualdade de condiçôes e possibilidades em todas as camadas sociais. Para uma formação cidadá, torna-se imprescindível a busca pela igualdade entre as pessoas respeitando suas individualidades.

Próximo deste tema envolvendo inclusão social, Botelho e Souza ${ }^{30}$ discutem sobre o fenômeno bullying, o qual ocorre no contexto de uma relação desigual de poder. Esta violência se manifesta sob forma de brincadeiras, apelidos, trotes, gozaçóes e agressóes físicas, em que todas as formas de atitudes agressivas, intencionais e repetidas, ocorrendo sem motivação evidente e veladamente, e são adotadas por um ou mais estudantes contra outro(s).

Oliveira e Votre ${ }^{31}$ realizaram um estudo sobre o bullying e concluíram que o ambiente da Educação Física permite que esta discriminação ocorra. Os autores explicam que o bullying é um indício do quanto as pessoas estáo envolvidas com os estereótipos culturais, que sáo produzidos conjuntamente por homens e mulheres na sociedade familiar e, sobretudo escolar, em que as crianças e os jovens os acabam reproduzindo. Matos, Zoвoli e Mezzaroba ${ }^{32}$ analisaram como se manifestava o processo de bullying na vida dos alunos considerados 
obesos por seus agressores na Educação Física escolar. Os autores sugeriram que, para combater a violência manifestada por meio do bullying, nas aulas de Educaçáo Física e no contexto escolar, fazse necessária uma interaçáo conjunta de conivência entre alunos, funcionários, pais, professores e dirigentes, mediada por uma sensibilização que favoreça a cultura do acolhimento e do respeito no convívio com o diferente.

No combate ao bullying, Oliveira e Votre ${ }^{31}$ defendem que os educadores devem ficar atentos aos sinais de injustiça e crueldade e interferir pela conversa com o grupo, oferecendo oportunidades para a reflexão, a tomada de posição e a superação do problema pela ampliação dos olhares. Para ВотеLно e SouzA ${ }^{30}$, é necessário que o professor de Educação Física desenvolva estratégias para prevenção desse fenômeno durante toda a educação básica, desde a educação infantil até o último ano do ensino médio; e, para que estas estratégias sejam bem sucedidas, devem ser incluídos, além dos alunos, o corpo docente, os funcionários da escola, os familiares e a comunidade.

Uma vez iniciadas, na educação infantil, estas estratégias de prevenção e de controle ao bullying deverão acompanhar o estudante pelas etapas de ensino fundamental e médio, sendo inseridas como conteúdo específico da disciplina de Educação Física. Portanto, o fenômeno bullying deve ser abordado transversalmente durante toda a educação escolar do aluno, visando, entre outras questôes, o convívio com a diferença. Para além da escola, pensando na educaçáo de forma mais ampla, defendemos que isto é possível, inclusive, a partir do ensino da Bioética tanto na escola ${ }^{33,34}$, quanto em cursos de graduação e de pós-graduação em Educação Física e cursos da área das $\mathrm{CMH}$, entre outros campos da saúde.

Aguiar e Duarte ${ }^{29}$ refletiram sobre a formação do profissional em Educação Física, que culturalmente vem privilegiando o desenvolvimento de capacidades e habilidades físicas, priorizando o desempenho físico e técnico, lidando com o corpo como objeto de consumo. Contudo, os autores alertam que o papel do professor dessa área é acompanhar a evolução com uma postura ética diante das novas formas de consumo e com senso crítico, pois o papel do educador é ser um agente transformador da sociedade, não se comprometendo com a lógica do mercado, devendo vivenciar a cultura vigente com o discernimento de que, na sociedade de consumo, classista e competitiva, o "ter" ultrapassa o "ser" com valor ético.
Nesta perspectiva, outro tema relevante vem à tona: o racismo, retratado em estudos atuais ${ }^{35,36}$. Um deles, examinou a presença do racismo em uma escola pública municipal do estado de São Paulo, cujo foco prioritário de observação e análise foram as aulas de Educação Física, mas os demais ambientes escolares como espaços onde se perpetuam as relaçóes desiguais de poder também foram objeto de observaçãa ${ }^{35}$. O estudo apontou alguns dos mecanismos de exclusão que desautorizam determinadas pessoas e todas as suas representaçóes sociohistórico-culturais. Foi identificada uma identidade-referência fundada no modelo branco, masculino e euro-estadunidense que há décadas permeia a construçâo das subjetividades de alunas e alunos levantando a suspeita do desencadeamento do processo, aqui conceituado invisibilizaçáo (o modelo negro é visível, porém sua cultura não é legitimada, tornando-o invisível). Nas entrevistas realizadas neste estudo ${ }^{35}$, as vítimas apontaram a presença frequente e contundente de racismo e, por sua vez, os professores e gestores, que possuem maiores condiçôes de resolver a situação, apontaram não perceber este fenômeno, demonstrando, assim, a necessidade de um estado de atenção constante para as desigualdades do cotidiano escolar, o que faz parte da função política docente. O que poderia ser combatido com a proposta de reinvindicação de uma Educação Física antirracista proposta por outro estudo, conduzido por Nobrega ${ }^{36}$, quem propóe, como parte de enfrentamento no combate ao racismo, às desigualdades e às discriminaçôes, que os saberes necessários produzidos pelo movimento negro reafirmem o direito à diferença na cultura corporal. Ambos os estudos, direta ou indiretamente, demonstram que o combate ao racismo não é uma tarefa fácil, pois se apresenta sutilmente e acomete suas vítimas de invisibilidade, criando consequentemente identidades hierarquicamente inferiorizadas.

Uma possibilidade para a conexáo entre Educação e Bioética está na capacitação do pleno exercício de cidadania de indivíduos e grupos desenvolvendo uma postura cidadã e crítica entre os discentes ${ }^{23}$. Nesta educação em todos os níveis, do ensino fundamental ao médio, ou graduaçôes e pós-graduaçóes, podem ser utilizados inúmeros meios como mesas-redondas, análise de casos reais e hipotéticos, seminários, recursos audiovisuais, conversas informais, encontros comunitários e dramatização ${ }^{23}$. Para instituiçóes que oferecem os cursos da área da saúde, estes deveriam estimular 
uma aproximação precoce dos estudantes com os temas bioéticos de interesse de cada profissão por meio de cursos, jornadas, congressos e pesquisas durante toda a sua formação acadêmica ${ }^{12}$. O desafio da Bioética, portanto, é reconhecer uma situação de conflito, seja ela de ordem biomédica, ambiental, política ou cultural e estimular os que a convocaram para uma reflexão crítica ${ }^{23}$.

Desta forma, a Bioética está presente em diversos temas da área da Educação Física e do corpo em movimento intencional, como os apontados nos estudos apresentados e discutidos neste ensaio, demonstrando a importância do ensino da Bioética nos cursos de graduação e pós-graduação em Educação Física. Assim, concordamos com Silveira et al. ${ }^{16}$ que é um direito dos discentes o acesso à educação de temas relacionados aos direitos humanos e à própria educação.

\section{Considerações finais}

Este ensaio teórico procurou demonstrar a importância do ensino em Bioética para os profissionais da área da Educação Física, em especial, apresentando alguns conflitos bioéticos existentes nesta área, visando sensibilizá-los a refletirem eticamente sobre a ação a ser tomada frente a tais conflitos. Alguns deles envolvem os direitos humanos, tais como qualquer tipo de discriminação, como por exemplo: o acesso e a igualdade, discutidos nos estudos sobre inclusão social e o direito ao acesso à educação de qualidade; bem como o bullying e o racismo. Nesta perspectiva, defendemos o ensino da Bioética em todas as esferas da educação e, aqui, em particular, nos cursos de graduação e de pósgraduação em Educação Física.
Para tanto, foi apresentada a Bioética de enfoque latino-americano como proposta para analisar os Direitos Humanos no Brasil, no contexto da Educação Física. A Bioética de enfoque latino-americano é entendida como uma proposta pertinente para a reflexão crítica de temas que dizem respeito aos direitos humanos e ao espaço para a capacitação do exercício da cidadania, representadas, neste ensaio, pela Bioética de Proteção e pela Bioética de Intervenção. Com isso, este ensaio pretendeu estimular o debate e as aproximaçóes aos conflitos bioéticos que os avanços tecnológicos promovem nas profissóes da área da saúde em geral e, da Educação Física, em particular, estimulando os profissionais envolvidos a refletirem etica e criticamente, a luz dos direitos humanos.

\section{Abstract}

Human rights and access to bioethics education for graduation and post-graduation in physical education

This theoretical essay aims to: 1) demonstrate the importance of teaching Bioethics to professionals in the field of Physical Education; (2) defend the teaching of Bioethics in undergraduate and graduate courses in Physical Education; and (3) to present Bioethics with a Latin American focus as a proposal to analyze Human Rights in Brazil in the context of Physical Education. For this, we understand the theoretical essay as a presentation of a reflective and interpretive nature, of a personal judgment of the researchers themselves, based on the existing scientific literature on the topic addressed. Bioethics associated with Human Movement Sciences, high-performance sports, physical activity, and health brings up complex issues such as body image, anorexia, the vulnerability of the professional athlete and bioethical conflicts involved in the relationship between the professional athlete and the professional health care, early sports initiation, in addition to the importance of the physical education professional as an educational agent inserted in public policies for a society that is sedentary and stigmatized. Because of the approximations of bioethical conflicts that technological advances promote in health professions, there is a need to discuss the importance of teaching Bioethics in the academic training of health professionals and, thus, prepare them to reflect on the possible ethical conflicts they will encounter during their professional practice. These, in turn, have a deep and complex relationship with human rights.

KeYwords: Bioethical Issues; Professional training; Superior education; Motor Activity

Rev Bras Educ Fís Esporte, (São Paulo) 2021J unho;35(nesp):47-54 


\section{Referências}

1. Tojal JB, Barbosa AP. A Ética e a bioética na preparação e na intervenção do profissional de Educação Física. Belo Horizonte: Casa da Educação Física, 2006.

2. Tojal JB. Contribuição dos organizadores. In: Tojal JB, Barbosa AP. A Ética e a bioética na preparaçáo e na intervenção do profissional de Educação Física. Belo Horizonte: Casa da Educação Física, 2006, p. 91.

3. Sergio M. Educaçáo física ou motricidade humana? Campinas: Papirus, 1989.

4. Tojal JB, Costa LP, Beresford H. Ética profissional na Educação Física. Rio de Janeiro: Shape: Confef, 2005.

5. Durand G. Introdução geral à bioética: história, conceitos e instrumentos. 4. ed. Nicolás Nyimi Campanário. São Paulo: Loyola, 2012.

6. Unesco - Organização das Naçóes Unidas para a Educação, Ciência e Cultura. Declaração Universal sobre Bioética e Direitos Humanos. Paris: Unesco; 2005.

7. Salvador T, Sampaio H, Palhares D. Análise textual da Declaração Universal sobre Bioética e Direitos Humanos. Rev Bioét. 2018;26:523-529.

8. Dos Santos IL. Igualdade, equidade e justiça na saúde à luz da bioética. Rev Bioét. 2020;28:229-238.

9. Figueiredo AM, Garrafa V, Portillo JAC. Ensino da bioética na área das ciências da saúde no Brasil: estudo de revisão sistemática. Interthesis. 2008;5:47-72.

10. Figueiredo AM. O ensino da bioética na pós-graduação stricto sensu da área de ciências da saúde no Brasil [tese]. Brasília: Universidade de Brasília, 2009.

11. Waltrick LT. O ensino da Bioética em um Programa de Pós-graduação em Ciências do Movimento Humano: uma investigação sobre o uso de filmes com foco na atividade física e saúde [Mestrado em Ciências do Movimento Humano]. Florianópolis (SC): Universidade do Estado de Santa Catarina, Centro de Saúde e Esportes, 2020. 127 p.

12. Paiva LM, Guilhem D, Sousa ALL. 2014). O Ensino da bioética na graduação do profissional de saúde. Medicina. 2014;47:357-369.

13. Waltrick LT, Stein F, Marinho A. Vulnerabilidade e bioética: discussôes sobre o filme Um homem entre gigantes. Rev Bioét. 2021;29:186-193. Disponível em: http://dx.doi.org/10.1590/1983-80422021291458.

14. Finkler M, Caetano JC, Ramos FRS. Um marco conceitual para o estudo da dimensão ética da formação profissional em saúde. In: Hellmann F, et al. Bioética e Saúde Coletiva: perspectivas e desafios contemporâneos. Curitiba: Prismas, 2013. p. 179.

15. Rego S, Palacios M. Contribuições para o planejamento e avaliação da bioética. Rev Bioét. 2017;25:234-243.

16. Silveira SR, Freudenheim AM, Bassi P, Oliveira JA de. Núcleo de Direitos Humanos da Escola de Educação Física e Esporte da USP: uma perspectiva educativa. Rev Bras Educ Fís Esporte. 2020;34(Esp.):1-9. Disponível em: https://www.revistas.usp. br/rbefe/article/view/173137. Acesso em: 7 dez 2020.

17. Rebustini F, Machado AA. Modelo hierárquico de vulnerabilidade no esporte. Pensar Prát. 2016;19:939-952.

18. Alcaíde AR. Conflitos bioéticos no atendimento clínico do atleta profissional [dissertação]. São Paulo: Centro Universitário São Camilo, 2007.

19. Rebello DS. Iniciação esportiva: uma abordagem bioética. In: Salles AA, organizadores. Bioética: velhas barreiras, novas fronteiras. Belo Horizonte: Mazza, 2011, p. 257-270.

20. Silva MRS. Doping: consagração ou profanação. Rev Bras Ciênc Esporte. 2005;27:9-22.

21. Meneghetti FK. Documentos e Debates: O que é um Ensaio-Teórico? RAC. 2011;15:320-332.

22. Gaya a. Principais concepçôes metodológicas da investigação científica aplicadas às ciências do Movimento humano. In: Gaya A, organizador. Ciências do Movimento Humano: introdução à metodologia da pesquisa. Porto Alegre: Artmed, 2008. p. 41-50.

23. Silva LFA, Wanderley CS, Cunha TR. Educação e Bioética: desafios do ensino em Bioética no Brasil. In: Hellmann F, et al. Bioética e Saúde Coletiva: perspectivas e desafios contemporâneos. Curitiba: Prismas. p. 163

24. Schramm FR. Bioética da proteção: ferramenta válida para enfrentar problemas morais na era da globalização. Rev Bioét. 2008; 16:11-23

25. Garrafa V, Porto D. Intervention bioethics: a proposal for peripheral countries in a context of power and injustice. Bioethics. 2003;17:399-416.

26. Porto D, Garrafa V. Bioética de intervenção: consideraçóes sobre a economia de mercado. Rev Bioét. 2005;13:111-123.

27. Bernardes LCG, Maior IMMDL, Spezia CH, Araujo TCCFD. Pessoas com deficiência e políticas de saúde no Brasil: reflexôes bioéticas. Ciênc. Saúde Colet. 2009;14:31-38.

28. Barroso ALR, Darido SC. Escola, educação física e esporte: possibilidades pedagógicas. Rev Bras Educ Fís Esporte Lazer Dança. 2006;4:101-114.

29. Aguiar JS de, Duarte É. Educação inclusiva: um estudo na área da educação física. Rev Bras Educ Espec. 2005;11:223-240. 


\section{Teixeira LW \& Marinho A}

30. Botelho RG, De Souza JMC. Bullying e educação física na escola: características, casos, conseqüências e estratégias de intervenção. J Phys Educ. 2007;139:58-70.

31. De Oliveira FF, Votre SJ. Bullying nas aulas de educação física. Movimento. 2006;12:173-197.

32. Matos KS, Zoboli F, Mezzaroba C. O bullying nas aulas de educação física escolar: corpo, obesidade e estigma. Atos Pesq Educ. 2012;7:272-295.

33. Fischer ML, da Cunha TR, Roth ME, Martins GZ. Caminho do diálogo: uma experiência bioética no ensino fundamental. Rev Bioét. 2017;25:89-100. Disponível em: http://dx.doi.org/10.1590/1983-80422017251170.

34. Messias TH, Anjos MD, Rosito MMB. Bioética e educação no ensino médio. Bioethikos. 2007;1:96-102.

35. Lins Rodrigues AC. Corpos e culturas invisibilizados na escola: racismo, aulas de Educaçáo Física e insurgência multicultural [tese]. São Paulo: Faculdade de Educação, 2013.

36. Nobrega CCS. Por uma educação física antirracista. Rev Bras Educ Fís Esporte. 2020;34(Esp.):51-6. Disponível em: https:// www.revistas.usp.br/rbefe/article/view/173145.

ENDEREÇO

Luciana Waltrick Teixeira

Universidade do Estado de Santa Catarina

Rua Abel Capella, 368/ 15

88080-250 - Florianópolis - SC - Brasil

Recebido: 09/ 12/ 2020

Aceito: 18/ 12/ 2020

E-mail: lu.twaltrick@gmail.com 